\title{
Risk of Developing Metabolic Syndrome Is Affected by Length of Daily Siesta: Results from a Prospective Cohort Study
}

\author{
Anne Katherine Gribble ${ }^{1,2,3} \mathbb{D}$, Carmen Sayón-Orea ${ }^{2,4,5,6}$, Maira Bes-Rastrollo ${ }^{2,4,6} \mathbb{D}$, Stefanos N. Kales ${ }^{7,8} \mathbb{D}$, \\ Ryutaro Shirahama 7,9,10, Miguel Ángel Martínez-González 2,4,6,11 (D) and Alejandro Fernandez-Montero 4,7,12,*(D)
}

1 School of Medicine, University of Sydney, Camperdown 2050, Australia; agri5188@uni.sydney.edu.au

2 Department of Preventive Medicine and Public Health, School of Medicine, University of Navarra, 31008 Pamplona, Spain; msayon@unav.es (C.S.-O.); mbes@unav.es (M.B.-R.); mamartinez@unav.es (M.Á.M.-G.)

3 Illawarra and Shoalhaven Local Health District, NSW Health, Wollongong 2500, Australia

4 Navarra Institute for Health Research (IdiSNa), 31008 Pamplona, Spain

5 Navarra Public Health Institute, 31003 Pamplona, Spain

6 CIBERobn, Instituto de Salud Carlos III, 28029 Madrid, Spain

7 Department of Environmental Health, Harvard T.H Chan School of Public Health, Boston, MA 02115, USA; stefokali@aol.com (S.N.K.); md.shirahama@live.jp (R.S.)

8 Department of Occupational Medicine, Cambridge Health Alliance, Harvard Medical School, Cambridge, MA 02139, USA

9 Department of Public Health, Graduate School of Medicine, Juntendo University, Tokyo 113-8421, Japan

10 Faculty of Science and Technology, Keio University, Kanagawa 223-8522, Japan

11 Department of Nutrition, Harvard T.H Chan School of Public Health, Boston, MA 02115, USA

check for updates

Citation: Gribble, A.K.; Sayón-Orea, C.; Bes-Rastrollo, M.; Kales, S.N.; Shirahama, R.; Martínez-González, M.Á.; Fernandez-Montero, A. Risk of Developing Metabolic Syndrome Is Affected by Length of Daily Siesta: Results from a Prospective Cohort Study. Nutrients 2021, 13, 4182. https://doi.org/10.3390/nu13114182

Academic Editor: Maria D. Mesa

Received: 28 October 2021

Accepted: 19 November 2021

Published: 22 November 2021

Publisher's Note: MDPI stays neutral with regard to jurisdictional claims in published maps and institutional affiliations.

Copyright: (c) 2021 by the authors. Licensee MDPI, Basel, Switzerland. This article is an open access article distributed under the terms and conditions of the Creative Commons Attribution (CC BY) license (https:/ / creativecommons.org/licenses/by/ $4.0 /)$.
12 Department of Occupational Medicine, University of Navarra Clinic, Av. Pio XII, 36, 31008 Pamplona, Spain

* Correspondence: afmontero@unav.es; Tel.: +34-948-255400; Fax: +34-948-296500

\begin{abstract}
Background: Siesta has been associated with increased incidence of cardiovascular disease but the mechanism remains unclear. New studies into the relationship between siesta and metabolic syndrome have identified siesta length as a crucial differential, suggesting that siesta less than $40 \mathrm{~min}$ is associated with decreased risk of metabolic syndrome, while longer siesta is associated with increased risk. We aimed to investigate the effect of siesta duration on development of metabolic syndrome in a Mediterranean population using a prospective cohort study design. Methods: Our sample consisted of 9161 participants of the SUN cohort without components of metabolic syndrome at baseline. Siesta exposure was assessed at baseline and the development of metabolic syndrome components was assessed after an average 6.8 years of follow-up. We estimated odds ratios and fitted logistic regression models to adjust for potential cofounders including night-time sleep duration and quality, as well as other diet, health, and lifestyle factors. Results: We observed a positive association between average daily siesta $>30 \mathrm{~min}$ and development of metabolic syndrome $(\mathrm{aOR}=1.39$ CI: 1.03-1.88). We found no significant difference in risk of developing metabolic syndrome between the group averaging $\leq 30 \mathrm{~min}$ of daily siesta and the group not taking siesta (aOR $=1.07 \mathrm{CI}$ : $0.83-1.37$ ). Further analysis suggested that average daily siesta $<15 \mathrm{~min}$ may reduce risk of metabolic syndrome. Conclusions: Our study supports the J-curve model of the association between siesta and risk of metabolic syndrome, but suggests the protective effect is limited to a shorter range of siesta length than previously proposed.
\end{abstract}

Keywords: siesta; nap; metabolic syndrome; obesity; dyslipidaemia; hypertension

\section{Introduction}

Siesta is a custom that involves lying down to rest for a few minutes to a couple of hours after having lunch. It is often perceived as a cultural practice of Mediterranean and Asian nations, but any review of the evidence reveals that it is far more widespread. Large studies estimate that more than $28 \%$ of the British populace take afternoon naps [1]-a 
figure which climbs above $40 \%$ in Switzerland, the Nordic countries, and the United States of America [2-6]. In this light, the siesta can be reconsidered a modern phenomenon, coinciding with the global reduction in night-time sleep hours and increased use of electronic devices, as well as the dominant neoliberal emphasis on economic productivity and trends that encourage working from home.

Studies investigating the health impacts of siesta often focus on neuropsychological outcomes: for example, whether a short siesta will improve post-nap mentation $[7,8]$, or decrease sleepiness in drivers $[9,10]$. But there is also evidence that siesta affects the cardiovascular system. In 1987, Trichopolous et al. propounded the cardio-protective nature of siesta [11], however subsequent studies associated siesta with increased cardiovascular risk [12-15] and increased mortality [1,16-22]. This conflict, as well as the biological mechanisms responsible for it, remains unclear.

Metabolic syndrome is a clustering of cardiovascular risk factors: obesity, increased blood pressure, increased blood glucose, increased triglycerides, and lowered HDL. It is associated with increased risk of mortality [23,24], as well as type 2 diabetes mellitus [24-26], cancer [27,28], surgical complications [29,30], dementia [31,32], and heart failure [33]. Although metabolic syndrome is not considered a disease, research into its prevention is crucial for human health.

We aimed to use a prospective cohort study design to examine the effect of siesta on the development of metabolic syndrome. Most prior investigations into this relationship relied on cross-sectional data and were therefore unable to establish direction of causation. Our study follows a 2016 systematic review and meta-analysis, which found siesta under 40 min protective against metabolic syndrome and type 2 diabetes mellitus [34], as well as a 2013 prospective study in our own cohort, which found a $30 \mathrm{~min}$ siesta protective against obesity [35].

\section{Methods}

\subsection{Study Design}

The study is a prospective cohort study from the Seguimiento Universidad de Navarra (SUN) cohort. The SUN cohort is a large cohort comprising graduates from Spanish universities. It focusses on the study of diet and lifestyle, and related health outcomes. Recruitment began in 1999 and remains open indefinitely. Graduates are invited to participate upon leaving university, or through alumni and regional professional organizations. Over 50\% of participants are health professionals. All data are self-reported. Upon entry into the cohort, participants complete a detailed baseline questionnaire, and shorter follow-up questionnaires are distributed every two years. Full details of the study methods have been published elsewhere [36].

\subsection{Ethics}

Ethics approval for the SUN cohort study was granted by the Institutional Review Board of the University of Navarra (2001_30). Submission of a completed baseline questionnaire is interpreted as evidence of free and informed consent, data are anonymized, and participants may withdraw from the study at any time.

\subsection{Study Sample}

We used the most current SUN database available at the time of analysis, dating from December 2019 and numbering 22,894 participants.

Figure 1 depicts the selection of the study sample. Participants were excluded from the sample if:

- They did not have outcome data for any component of metabolic syndrome;

- They met criteria for any component of metabolic syndrome at baseline;

- Their baseline questionnaire responses did not meet minimum quality standards, as assessed by whether their Food Frequency Questionnaire yielded realistic values for energy intake [37]; 
- $\quad$ They did not have baseline data about how long they slept at night.

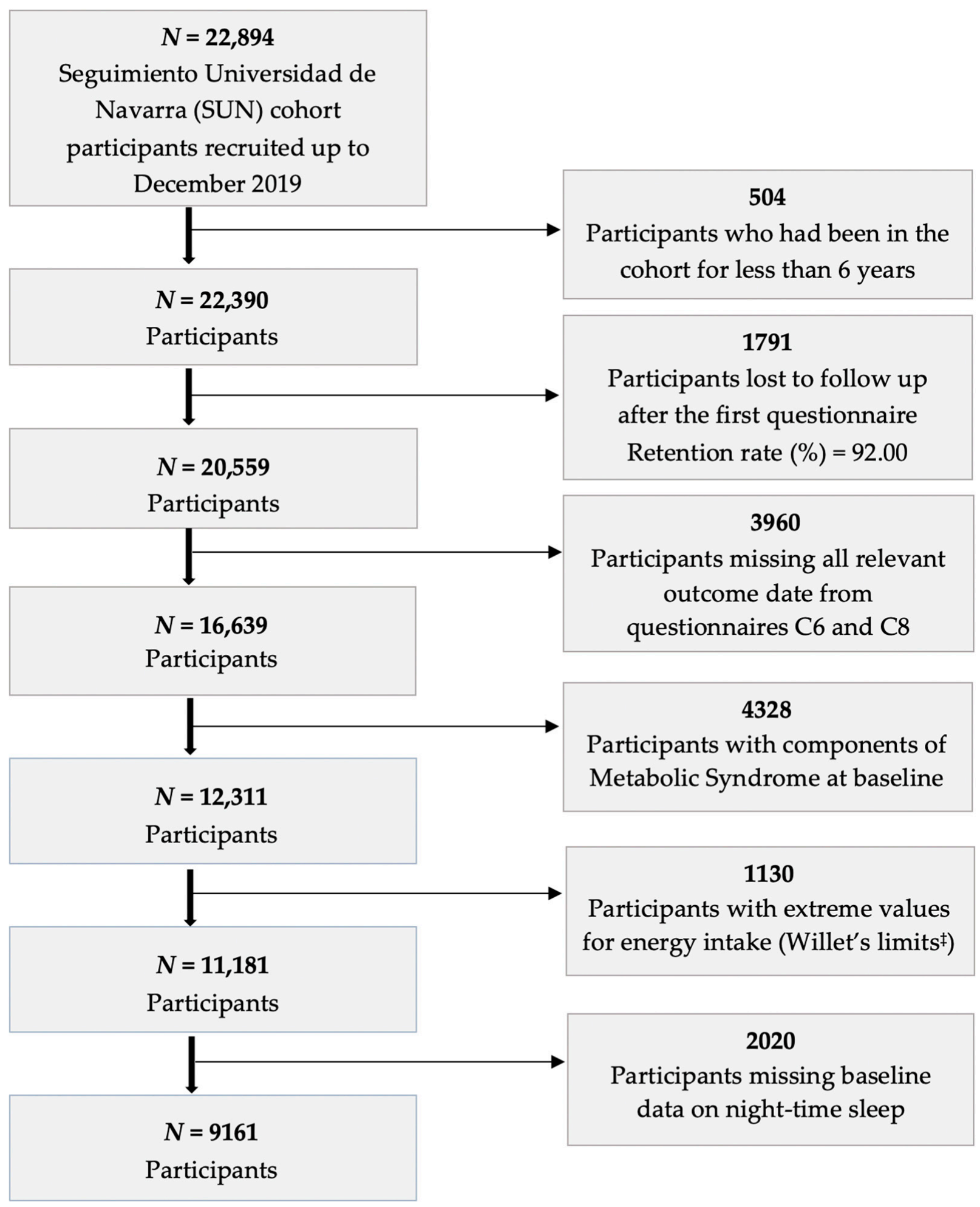

Figure 1. Flowchart depicting the selection process among participants of the SUN project (Seguimiento Universidad de Navarra, University of Navarra Follow-up) included in the present analyses. Navarra, Spain, 1999-2019. ‡ Willet 2012.

Our selection criteria allowed that a participant was deemed not to meet obesity criteria for metabolic syndrome if intercurrent pregnancy affected the calculation of body mass index (BMI). 


\subsection{Exposure Assessment}

Data on siesta habit were collected on the baseline questionnaire. Participants were asked about the average time they had spent doing various activities over the past year. Answer options ranged from "Never" through values from " $<30$ min per day" to " $9+$ hours per day". Separate answers were provided for weekdays versus weekends. The data collection related to siesta has been validated in a subsample of the cohort using prospective records (intraclass correlation coefficients 0.68) [35].

We calculated average daily siesta time as a continuous variable, then transformed it into an ordinal variable with three categories: No Siesta, Short Siesta (less than or equal to $30 \mathrm{~min}$ ), and Long Siesta (more than $30 \mathrm{~min}$ ).

\subsection{Outcome Assessment}

Data related to components of metabolic syndrome were assessed on the third and fourth questionnaires, distributed approximately six and eight years after entry into the cohort. Metabolic syndrome and its components were defined according to the Harmonizing Definition [25]. Presence of each component was evaluated as a categorical yes/no variable, as was metabolic syndrome itself. Data were primarily drawn from the third questionnaire, however where measurements were missing, we attempted to recuperate them from the fourth questionnaire. Any data that remained missing after this process were assumed not to meet criteria for metabolic syndrome.

To assess metabolic syndrome components, waist circumference was defined in accordance with the International Diabetes Federation cut-offs for abdominal obesity in Europids: $\geq 80 \mathrm{~cm}$ in women and $\geq 94 \mathrm{~cm}$ in men [25]. Participants were provided with a tape measure and instructions for measuring waist and hip circumference. These selfmeasured and self-reported measurements for waist circumference have been validated in our cohort [38]. For any participant without waist circumference data, BMI $\geq 30 \mathrm{~kg} / \mathrm{m}^{2}$ was used as criteria to determine obesity.

High blood glucose was defined as fasting glucose $\geq 100 \mathrm{mg} / \mathrm{dL}$. Participants who reported a new diagnosis of diabetes, or who used insulin or oral anti-hyperglycaemic medications were also considered to fulfil criteria.

Participants met criteria for elevated blood pressure if they had systolic blood pressure of $\geq 130 \mathrm{mmHg}$, diastolic blood pressure of $\geq 85 \mathrm{mmHg}$, used anti-hypertensive medications, or had a current diagnosis of hypertension.

Participants met criteria for high triglycerides if they reported a triglyceride level $\geq 150 \mathrm{mg} / \mathrm{dL}$, or if they took fibrate medication or fatty acid supplements.

Low HDL cholesterol was defined as HDL $<40 \mathrm{mg} / \mathrm{dL}$ for males, and HDL $<50$ $\mathrm{mg} / \mathrm{dL}$ for females.

\subsection{Covariables}

Information on relevant covariables and potential confounders was collected on the baseline questionnaire. Categorical covariables included sex, employment status (fulltime/part-time/unemployed), special diets (yes/no), and medical diagnoses (yes/no for each of cardiovascular disease, cancer, depression and obstructive sleep apnea). Continuous covariables included length of tertiary study (years), working hours (hours/week), frequency of lunch at home (days), night-time sleep (hours), television viewing time (hours), smoking pack years (years), alcohol intake (g/day), social time (hours/day), and preceding weight gain $(\mathrm{kg})$. Ordinal covariables included snoring (no/sometimes/yes), tendency to stress (range 0-10), year of entry into the cohort (1999-2014), and Mediterranean Diet Score (range 0-9) [39]. Covariables treated in quartiles included age (years), total daily energy intake (kcal), daily coffee intake (cups), and physical activity (METs/week). These covariables were treated in quartiles because, if treated as continuous variables, the wide distribution of responses made analysis so computationally intensive as to prohibit the inclusion of other covariables. Regression-based multiple imputation was used to impute 
missing values where required (working hours, lunch at home, television viewing, smoking pack years, BMI, social time, preceding weight gain, and tendency to stress).

\subsection{Statistical Analysis}

We estimated the crude odds ratios and associated $95 \%$ confidence interval (CI) for the development of metabolic syndrome using No Siesta as reference category. Next, we fitted logistic regression models to control for confounders and estimated adjusted odds ratios and 95\% CI under two models: first adjusting for age and sex alone, then adjusting for the complete list of potential confounders. We also estimated the multivariate-adjusted odds ratio using short siesta as the reference category. We used logistic regression models to estimate multivariate-adjusted odds ratios for the development of each component of metabolic syndrome.

We assessed for effect modification by age, sex, sleep disorders (insomnia and obstructive sleep apnea), and adherence to or divergence from the recommended night-time sleep duration of 7-8 hours [40]. We used the test for likelihood ratio to estimate the $p$ value for interaction.

For sensitivity analyses, we re-estimated multivariate-adjusted odds ratios using an alternate categorization of siesta exposure, focused on frequency of exposure, rather than daily average. These categories of siesta were: Never, Once or twice a week, Most days, Short Siesta once or twice a week, Short Siesta most days, Long Siesta once or twice a week, and Long Siesta most days.

All $p$ values presented are two-tailed; $p<0.05$ was considered statistically significant. Statistical analysis was completed using STATA/MP 14.1.

\section{Results}

Out of 9161 participants included in our study ( $68.3 \%$ females, mean age $36.1 \pm 10.5)$, siesta prevalence was $59.4 \%$ and 375 incident cases of metabolic syndrome $(4.1 \%)$ were observed after a mean follow-up of 6.8 years.

Table 1 compares the baseline characteristics of participants across our total sample and in each category of siesta. Prevalence rates of cardiovascular disease, obstructive sleep apnea, and cancer were low $(<2.5 \%)$ across the entire sample and in each group, although prevalence of cardiovascular disease and sleep apnea increased with longer siesta. Increased length of siesta also corresponded with increased prevalence of insomnia, increased prevalence of depression, increased energy and alcohol intake, increased smoking pack years, and more daily television. Compared to the total sample, the Long Siesta group had a higher proportion of men (only $66.93 \%$ were women as compared to $68.92 \%$ across the total sample) and reduced working hours ( $35.4 \mathrm{~h} / \mathrm{wk}$ compared to $36.8 \mathrm{~h} / \mathrm{wk}$ for the total sample).

Table 1. Baseline characteristics of sample participants.

\begin{tabular}{|c|c|c|c|c|c|}
\hline Characteristic & Total Sample & $\begin{array}{l}\text { No Siesta } \\
\text { (0 min/Day) }\end{array}$ & $\begin{array}{c}\text { Short Siesta } \\
(\leq 30 \mathrm{~min} / \text { Day })\end{array}$ & $\begin{array}{l}\text { Long Siesta } \\
\text { (>30 min/Day) }\end{array}$ & $p$ \\
\hline N & 9161 & 3719 & 3897 & 1545 & \\
\hline Women (\%) & $68.92 \%$ & $69.86 \%$ & $67.33 \%$ & $66.93 \%$ & 0.03 \\
\hline Age (years) $(\mathrm{M} \pm \mathrm{SD})$ & $36.1 \pm 10.5$ & $35.3 \pm 10.3$ & $36.9 \pm 10.1$ & $36.1 \pm 11.6$ & $<0.001$ \\
\hline Year of entry into cohort $(\mathrm{M} \pm \mathrm{SD})$ & $2003 \pm 2.9$ & $2002 \pm 2.9$ & $2003 \pm 3.0$ & $2003 \pm 2.8$ & $<0.001$ \\
\hline Years of tertiary study (years) $(\mathrm{M} \pm \mathrm{SD})$ & $5.1 \pm 1.5$ & $5.1 \pm 1.5$ & $5.1 \pm 1.5$ & $4.9 \pm 1.4$ & $<0.001$ \\
\hline \multicolumn{6}{|l|}{ Employment status: } \\
\hline Full-time $(\%)$ & $72.76 \%$ & $68.73 \%$ & $77.34 \%$ & $70.94 \%$ & \multirow{3}{*}{$<0.001$} \\
\hline Part-time (\%) & $9.26 \%$ & $10.11 \%$ & $8.83 \%$ & $8.28 \%$ & \\
\hline Other $(\%)$ & $17.98 \%$ & $21.16 \%$ & $13.83 \%$ & $20.78 \%$ & \\
\hline Working hours (h/wk) (M $\pm \mathrm{SD})$ & $36.8 \pm 16.7$ & $36.2 \pm 17.5$ & $38.0 \pm 15.6$ & $35.4 \pm 17.2$ & $<0.001$ \\
\hline Lunch at home (days/wk) $(\mathrm{M} \pm \mathrm{SD})$ & $5.5 \pm 2.1$ & $5.4 \pm 2.1$ & $5.4 \pm 2.1$ & $5.9 \pm 1.7$ & $<0.001$ \\
\hline Night-time sleep (h/night) $(\mathrm{M} \pm \mathrm{SD})$ & $7.4 \pm 0.9$ & $7.4 \pm 0.9$ & $7.4 \pm 0.8$ & $7.3 \pm 1.1$ & $<0.001$ \\
\hline Daily television (h/day) $(\mathrm{M} \pm \mathrm{SD})$ & $1.6 \pm 1.3$ & $1.5 \pm 1.4$ & $1.5 \pm 1.0$ & $2.0 \pm 1.5$ & $<0.001$ \\
\hline
\end{tabular}


Table 1. Cont.

\begin{tabular}{|c|c|c|c|c|c|}
\hline Characteristic & Total Sample & $\begin{array}{l}\text { No Siesta } \\
\text { (0 min/Day) }\end{array}$ & $\begin{array}{l}\text { Short Siesta } \\
(\leq 30 \mathrm{~min} / \text { Day })\end{array}$ & $\begin{array}{l}\text { Long Siesta } \\
\text { (>30 min/Day) }\end{array}$ & $p$ \\
\hline Smoking pack-years (pack-year) $(\mathrm{M} \pm \mathrm{SD})$ & $4.6 \pm 7.8$ & $3.8 \pm 7.0$ & $4.8 \pm 7.8$ & $5.7 \pm 9.4$ & $<0.001$ \\
\hline Alcohol (g/day) $(\mathrm{M} \pm \mathrm{SD})$ & $5.8 \pm 8.3$ & $4.9 \pm 7.5$ & $6.3 \pm 8.3$ & $6.7 \pm 9.8$ & $<0.001$ \\
\hline Total energy intake (kcal/day) $(\mathrm{M} \pm \mathrm{SD})$ & $2362.2 \pm 594.4$ & $2351.6 \pm 592.6$ & $2362.0 \pm 590.4$ & $2388.3 \pm 608.3$ & 0.13 \\
\hline Coffee intake (cups / day) $(\mathrm{M} \pm \mathrm{SD})$ & $1.2 \pm 1.2$ & $1.3 \pm 1.3$ & $1.3 \pm 1.2$ & $1.1 \pm 1.3$ & $<0.001$ \\
\hline Mediterranean Diet Score (score out of 9) $(\mathrm{M} \pm \mathrm{SD})$ & $4.2 \pm 1.8$ & $4.0 \pm 1.8$ & $4.3 \pm 1.8$ & $4.3 \pm 1.8$ & $<0.001$ \\
\hline Special diets $(\%)$ & $6.27 \%$ & $6.16 \%$ & $6.21 \%$ & $6.67 \%$ & 0.77 \\
\hline Physical activity (METs-h/week) $(\mathrm{M} \pm \mathrm{SD})$ & $20.9 \pm 22.4$ & $20.7 \pm 22.5$ & $21.0 \pm 21.8$ & $21.2 \pm 23.5$ & 0.75 \\
\hline Social time $(\mathrm{h} /$ day $)(\mathrm{M} \pm \mathrm{SD})$ & $0.6 \pm 0.4$ & $0.5 \pm 0.4$ & $0.5 \pm 0.4$ & $0.6 \pm 0.4$ & $<0.001$ \\
\hline Prevalent cardiovascular disease (\%) & $0.67 \%$ & $0.59 \%$ & $0.69 \%$ & $0.78 \%$ & 0.73 \\
\hline Prevalent cancer $(\%)$ & $2.16 \%$ & $2.02 \%$ & $2.36 \%$ & $2.01 \%$ & 0.53 \\
\hline $\begin{array}{c}\text { Prevalent depression or use of antidepressant } \\
\text { medication (\%) }\end{array}$ & $10.53 \%$ & $9.49 \%$ & $10.37 \%$ & $13.46 \%$ & $<0.001$ \\
\hline Previous history of insomnia (\%) & $16.88 \%$ & $15.46 \%$ & $17.35 \%$ & $19.09 \%$ & $<0.001$ \\
\hline Obstructive sleep apnea (\%) & $0.75 \%$ & $0.67 \%$ & $0.80 \%$ & $0.84 \%$ & 0.75 \\
\hline Snoring (\%) & $13.66 \%$ & $11.86 \%$ & $14.32 \%$ & $16.31 \%$ & $<0.001$ \\
\hline Weight gain prior to $\mathrm{C} 0(\mathrm{~kg})(\mathrm{M} \pm \mathrm{SD})$ & $0.8 \pm 4.0$ & $0.7 \pm 4.0$ & $0.8 \pm 3.9$ & $1.0 \pm 4.1$ & 0.01 \\
\hline Tendency to stress $(0-10)(\mathrm{M} \pm \mathrm{SD})$ & $6.0 \pm 2.2$ & $6.0 \pm 2.2$ & $6.0 \pm 2.2$ & $6.0 \pm 2.2$ & 0.23 \\
\hline
\end{tabular}

Continuous variables are expressed as mean with standard deviation in parentheses and categorical variables are expressed as percentages.

Our odds ratio analysis for the development of metabolic syndrome according to length of siesta is presented in Table 2. We found a significant association between Long Siesta and the risk of metabolic syndrome when compared to reference category of No Siesta (multivariate-adjusted odds ratio $\mathrm{OR}=1.39$ ). The absolute risk for the development of metabolic syndrome was almost twice as high for Long Siesta (6.02\%) compared to No Siesta $(3.23 \%)$. There was no significant association between Long Siesta and metabolic syndrome when using Short Siesta as the reference category $(\mathrm{OR}=1.30)$.

Table 2. Adjusted odds ratios (aOR) ${ }^{*}$ and $95 \%$ confidence intervals (CI) for the development of metabolic syndrome according to siesta length in the SUN cohort.

\begin{tabular}{|c|c|c|c|}
\hline & \multicolumn{3}{|c|}{ Siesta Length } \\
\hline & No Siesta & Short Siesta ( $\leq 30 \mathrm{~min})$ & Long Siesta $(>30 \mathrm{~min})$ \\
\hline$N$ & 3719 & 3897 & 1545 \\
\hline Cases & 120 & 162 & 93 \\
\hline$\%$ Absolute risk (cases $/ N$ ) & $3.23 \%$ & $4.16 \%$ & $6.02 \%$ \\
\hline Crude OR $(95 \% \mathrm{CI})$ & 1 Ref. & $1.30(1.02-1.65)$ & $1.92(1.46-2.54)$ \\
\hline Age and Sex adjusted OR (95\% CI) & 1 Ref. & $1.15(0.89-1.47)$ & $1.59(1.19-2.13)$ \\
\hline Multivariable adjusted OR (95\% CI) & 1 Ref. & $1.07(0.83-1.37)$ & $1.39(1.03-1.88)$ \\
\hline Crude OR $(95 \%$ CI $)$ & $0.77(0.60-0.98)$ & 1 Ref. & $1.48(1.14-1.92)$ \\
\hline Age and Sex adjusted OR (95\% CI) & $0.87(0.68-1.12)$ & 1 Ref. & $1.39(1.05-1.83)$ \\
\hline Multivariable adjusted OR (95\% CI) & $0.94(0.73-1.21)$ & 1 Ref. & $1.30(0.98-1.73)$ \\
\hline
\end{tabular}

* Adjusted for sex, age, years of university, year of entry into cohort, working hours, lunch at home, hours of night-time sleep, daily TV, smoking pack-years, daily alcohol intake, total daily energy intake, daily coffee intake, Mediterranean Diet Score, special diets, physical activity, social time, prevalent cardiovascular disease, prevalent cancer, prevalent depression, prior history of insomnia, obstructive sleep apnea, snoring, weight gain prior to recruitment, tendency to stress.

Table 3 presents the multivariate-adjusted odds ratios and 95\% confidence intervals for development of each metabolic syndrome criteria. Obesity was the most frequently met criteria for metabolic syndrome (3662 cases; $40.0 \%$ ): absolute risk increased from No Siesta (37.6\%) to Short Siesta (40.9\%), and Long Siesta had the highest absolute risk (43.4\%). The multivariate-adjusted odds ratio for development of obesity under the condition of Long Siesta compared to No Siesta as reference category was 1.15 (95\% CI 1.01-1.32). Taking No Siesta as reference, the absolute risks of developing any of high triglycerides, hypertension or hyperglycemia also increased with increasing siesta length, however in every case the $\mathrm{CI}$ for the adjusted OR included the null hypothesis. For low HDL, absolute risk was greatest under the condition of Long Siesta but was lowest for Short Siesta rather 
than for No Siesta. However, the findings for HDL were not statistically significant as the CI for the adjusted OR crossed the null hypothesis.

Figure 2 presents our exploration of non-linearity in the relationship between siesta exposure and development of metabolic syndrome. The positive relationship between siesta duration and development of metabolic syndrome is dose dependent and increases the longer the siesta continues beyond $30 \mathrm{~min}$. However, for daily average siesta shorter than $15 \mathrm{~min}$, the point value for the adjusted OR suggests a possible protective effect though the finding is not significant $(\mathrm{aOR}=0.91,95 \% \mathrm{CI} 0.64-1.27)$.

Table 3. Adjusted odd ratios (aOR) * and 95\% confidence intervals (CI) for the development of metabolic syndrome criteria according to siesta length in the SUN cohort.

\begin{tabular}{|c|c|c|c|}
\hline \multicolumn{4}{|c|}{ Siesta Length } \\
\hline Metabolic Syndrome Criteria & No Siesta & Short Siesta ( $\leq 30 \mathrm{~min})$ & Long Siesta (>30 min) \\
\hline \multicolumn{4}{|c|}{ Obesity (Waist Circumference $\geq 80 \mathrm{~cm}$ in women or $\geq 94 \mathrm{~cm}$ in men or BMI $\geq 30 \mathrm{~kg} / \mathrm{m}^{2}$ ) } \\
\hline$N^{* *}=9161$ & $N=3719$ & $N=3897$ & $N=1545$ \\
\hline Cases $=3662$ & 1399 & 1593 & 670 \\
\hline$\%$ Absolute risk $=39.97 \%$ & $37.62 \%$ & $40.88 \%$ & $43.37 \%$ \\
\hline Multivariable adjusted OR (95\% CI) & 1 Ref. & $1.04(0.94-1.15)$ & $1.15(1.01-1.32)$ \\
\hline \multicolumn{4}{|c|}{ High triglycerides (Serum triglycerides $\geq 150 \mathrm{mg} / \mathrm{dL}$ or pharmacological treatment for high triglycerides) } \\
\hline$N^{* *}=5345$ & $N=2149$ & $N=2294$ & $N=902$ \\
\hline Cases $=417$ & 142 & 185 & 90 \\
\hline$\%$ Absolute risk $=7.80 \%$ & $6.61 \%$ & $8.06 \%$ & $9.98 \%$ \\
\hline Multivariable adjusted OR (95\% CI) & 1 Ref. & $1.10(0.88-1.39)$ & $1.33(1.00-1.76)$ \\
\hline \multicolumn{4}{|c|}{ Low HDL cholesterol (Serum HDL cholesterol $<50 \mathrm{mg} / \mathrm{dL}$ in women or $<40 \mathrm{mg} / \mathrm{dL}$ in $\mathrm{men}$ ) } \\
\hline$N^{* *}=4705$ & $N=1856$ & $N=2054$ & $N=795$ \\
\hline Cases $=488$ & 199 & 193 & 96 \\
\hline$\%$ Absolute risk $=10.37 \%$ & $10.72 \%$ & $9.39 \%$ & $12.08 \%$ \\
\hline Multivariable adjusted OR (95\% CI) & 1 Ref. & $0.90(0.73-1.10)$ & $1.13(0.87-1.47)$ \\
\hline \multicolumn{4}{|c|}{ Hypertension (Systolic blood pressure $\geq 130 \mathrm{mmHg}$ or diastolic blood pressure $\geq 85 \mathrm{mmHg}$ or pharmacological treatment for hypertension) } \\
\hline$N^{* *}=7724$ & $N=3079$ & $N=3316$ & $N=1329$ \\
\hline Cases $=1486$ & 550 & 654 & 282 \\
\hline$\%$ Absolute risk $=19.24 \%$ & $17.86 \%$ & $19.72 \%$ & $21.22 \%$ \\
\hline Multivariable adjusted OR (95\% CI) & 1 Ref. & $1.01(0.88-1.15)$ & $1.09(0.92-1.30)$ \\
\hline \multicolumn{4}{|c|}{ Hyperglycaemia (Fasting glucose $\geq 100 \mathrm{mg} / \mathrm{dL}$ or pharmacological treatment for hyperglycaemia) } \\
\hline$N^{* *}=6616$ & $N=2615$ & $N=2855$ & $N=1146$ \\
\hline Cases $=759$ & 266 & 344 & 149 \\
\hline$\%$ Absolute risk $=11.47 \%$ & $10.17 \%$ & $12.05 \%$ & $13.00 \%$ \\
\hline Multivariable adjusted OR (95\% CI) & 1 Ref. & $1.09(0.92-1.30)$ & $1.10(0.88-1.38)$ \\
\hline
\end{tabular}

* Adjusted for sex, age, years of university, year of entry into cohort, working hours, lunch at home, hours of night-time sleep, daily TV, smoking pack-years, daily alcohol intake, total daily energy intake, daily coffee intake, Mediterranean Diet Score, special diets, physical activity, social time, prevalent cardiovascular disease, prevalent cancer, prevalent depression, prior history of insomnia, obstructive sleep apnea, snoring, weight gain prior to recruitment, tendency to stress. ${ }^{*}$ For each component, the number of participants is restricted to those with outcome data available for the specified component. Follow up time for each component of metabolic syndrome is as follows: 6.6 years for obesity, 6.8 years for fasting glucose, 6.7 years for blood pressure, 6.9 years for triglycerides and 6.9 years for HDL cholesterol.

Our stratified analysis (Table 4) identified a significant association between siesta and metabolic syndrome in participants who were younger than 50 years, participants without sleep disorders and participants whose night-time sleep duration was less than $7 \mathrm{~h}$ or more than $8 \mathrm{~h}$. No association between siesta and metabolic syndrome was found in stratified analysis for either men or women. We found no evidence of statistical interaction between age, sex, or sleep disorder. The results of our sensitivity analyses are presented in Supplementary Table. 


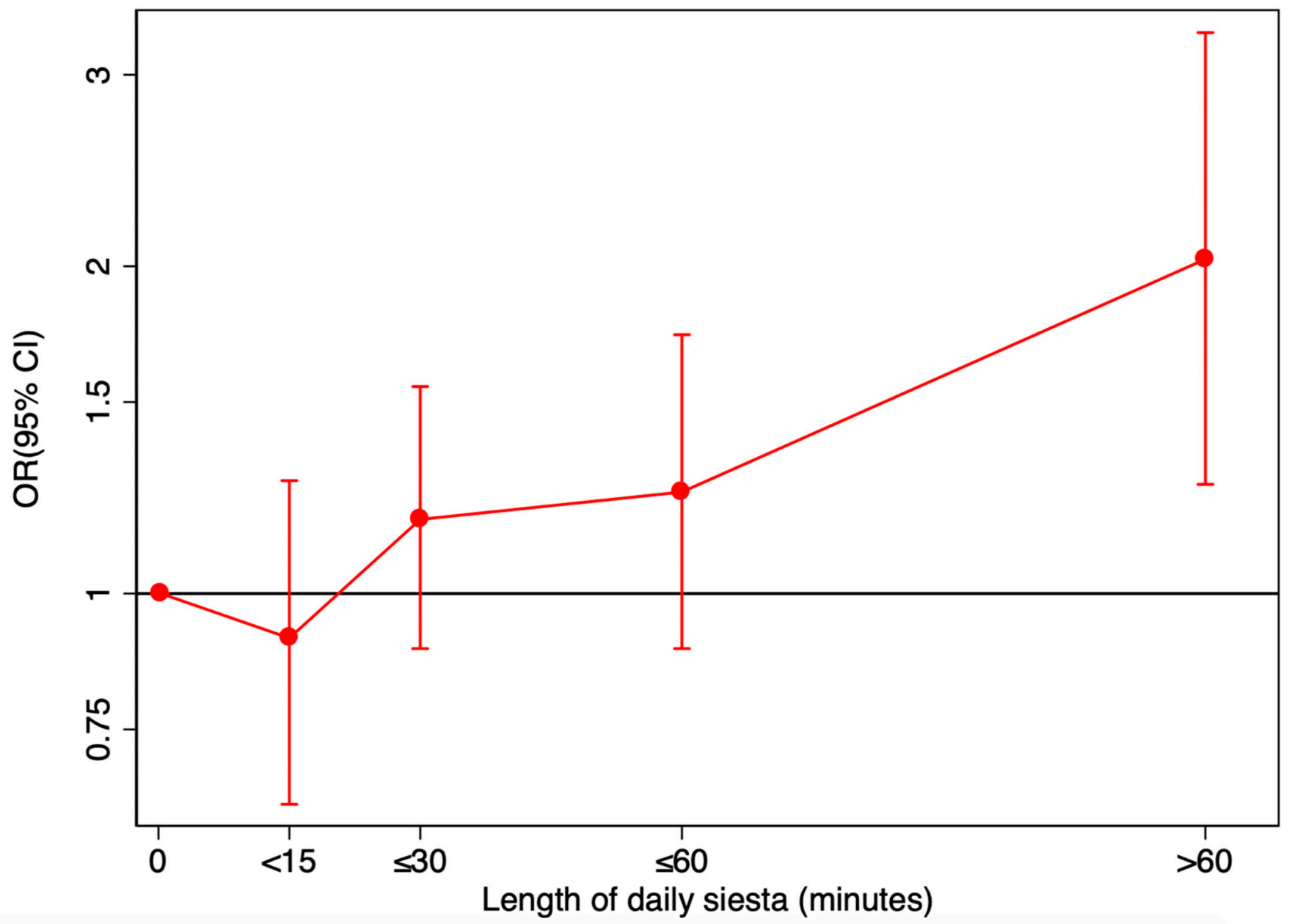

Figure 2. A non-linear relationship: Adjusted odd ratios (aOR) * and 95\% confidence intervals (CI) for the development of metabolic syndrome according to length of daily siesta in the SUN cohort. * Adjusted for sex, age, years of university, year of entry into cohort, working hours, lunch at home, hours of night-time sleep, daily TV, smoking pack-years, daily alcohol intake, total daily energy intake, daily coffee intake, Mediterranean Diet Score, special diets, physical activity, social time, prevalent cardiovascular disease, prevalent cancer, prevalent depression, prior history of insomnia, obstructive sleep apnea, snoring, weight gain prior to recruitment, tendency to stress.

Table 4. Analysis of effect modification: Adjusted odd ratios (aOR) * and 95\% confidence intervals (CI) for the development of the metabolic syndrome according to siesta length in the SUN cohort stratified by potential confounders.

\begin{tabular}{|c|c|c|c|c|}
\hline \multirow[b]{2}{*}{ Potential Modifier of Effect of Siesta } & \multicolumn{3}{|c|}{ Siesta Length } & \multirow[b]{2}{*}{$p$ for Interaction } \\
\hline & No Siesta & Short Siesta ( $\leq 30 \mathrm{~min})$ & Long Siesta (>30 min) & \\
\hline & $N=3719$ & $N=3897$ & $N=1545$ & \\
\hline Age & & & & 0.354 \\
\hline \multicolumn{5}{|l|}{ Age $<50$ years $(N=8080)$} \\
\hline$N$ & 3339 & 3422 & 1319 & \\
\hline Cases & 71 & 104 & 49 & \\
\hline $\mathrm{aOR}(95 \% \mathrm{CI})$ & 1 Ref. & $1.18(0.86-1.61)$ & $1.53(1.04-2.27)$ & \\
\hline \multicolumn{5}{|l|}{ Age $\geq 50$ years $(N=1081)$} \\
\hline$N$ & 380 & 475 & 226 & \\
\hline Cases & 49 & 58 & 44 & \\
\hline aOR $(95 \% \mathrm{CI})$ & 1 Ref. & $0.87(0.56-1.33)$ & $1.31(0.81-2.12)$ & \\
\hline Sex & & & & 0.368 \\
\hline \multicolumn{5}{|l|}{$\operatorname{Men}(N=2905)$} \\
\hline$N$ & 1121 & 1273 & 511 & \\
\hline Cases & 66 & 87 & 57 & \\
\hline $\mathrm{aOR}(95 \% \mathrm{CI})$ & 1 Ref. & $0.94(0.66-1.33)$ & $1.35(0.90-2.03)$ & \\
\hline
\end{tabular}


Table 4. Cont.

\begin{tabular}{|c|c|c|c|c|}
\hline \multicolumn{5}{|c|}{ Siesta Length } \\
\hline Potential Modifier of Effect of Siesta & No Siesta & Short Siesta ( $\leq 30 \mathrm{~min})$ & Long Siesta (>30 min) & $p$ for Interaction \\
\hline \multicolumn{5}{|l|}{ Women $(N=6256)$} \\
\hline$N$ & 2598 & 2624 & 1034 & \\
\hline Cases & 54 & 75 & 36 & \\
\hline aOR $(95 \% \mathrm{CI})$ & 1 Ref. & $1.20(0.83-1.73)$ & $1.45(0.92-2.29)$ & \\
\hline Sleep disorder & & & & 0.879 \\
\hline \multicolumn{5}{|l|}{ No sleep disorder $(N=7554)$} \\
\hline$N$ & 3118 & 3199 & 1237 & \\
\hline Cases & 94 & 124 & 68 & \\
\hline $\mathrm{aOR}(95 \% \mathrm{CI})$ & 1 Ref. & $1.10(0.83-1.47)$ & $1.42(1.01-2.01)$ & \\
\hline \multicolumn{5}{|l|}{ Sleep disorder $(N=1607)$} \\
\hline$N$ & 601 & 698 & 308 & \\
\hline Cases & 26 & 38 & 25 & \\
\hline aOR $(95 \% \mathrm{CI})$ & 1 Ref. & $1.00(0.58-1.71)$ & $1.27(0.68-2.38)$ & \\
\hline Night-time sleep duration & & & & 0.104 \\
\hline \multicolumn{5}{|c|}{$7-8 \mathrm{~h}$ of nightly sleep $(N=6358)$} \\
\hline$N$ & 2622 & 2837 & 899 & \\
\hline Cases & 85 & 117 & 47 & \\
\hline aOR $(95 \% \mathrm{CI})$ & 1 Ref. & $1.08(0.80-1.46)$ & $1.19(0.80-1.76)$ & \\
\hline \multicolumn{5}{|c|}{$<7$ or $>8$ h of nightly sleep $(N=2803)$} \\
\hline$N$ & 1097 & 1060 & 646 & \\
\hline Cases & 35 & 45 & 46 & \\
\hline aOR $(95 \% \mathrm{CI})$ & 1 Ref. & $1.06(0.66-1.71)$ & $1.71(1.04-2.80)$ & \\
\hline
\end{tabular}

* Adjusted for sex, age, years of university, year of entry into cohort, working hours, lunch at home, hours of night-time sleep, daily TV, smoking pack-years, daily alcohol intake, total daily energy intake, daily coffee intake, Mediterranean Diet Score, special diets, physical activity, social time, prevalent cardiovascular disease, prevalent cancer, prevalent depression, prior history of insomnia, obstructive sleep apnea, snoring, weight gain prior to recruitment, tendency to stress.

\section{Discussion}

\subsection{Interpretation of Findings Related to Metabolic Syndrome}

In this Mediterranean population of Spanish university graduates, we found a positive association between daily siesta of more than $30 \mathrm{~min}$ duration and the development of metabolic syndrome.

Our findings concur with previous studies into siesta and metabolic syndrome which have found that siesta of long duration increases the risk of metabolic syndrome, while siesta of shorter duration has indeterminate or even protective effect [3,34,41-44]. In a 2016 review and meta-analysis incorporating 288,883 participants, Yamada et al. demonstrated that the evidence points toward a J-curve relationship [34] and more recent studies also corroborate this suggestion [41]. Our study is important because it offers longitudinal evidence whereas all other contributing studies have been cross-sectional.

Beyond the general shape of the curve, agreement between previous studies has been limited. There is no convergence of opinion regarding what length of siesta is most protective, or at what length of siesta the association with metabolic syndrome becomes positive. In their review article, Yamada et al. observed a protective effect of siesta shorter than $40 \mathrm{~min}$, and can only be confident of a positive association between siesta and metabolic syndrome when duration exceeds 60 min daily. By contrast, in a more recent cross-sectional study, He et al. suggest that naps exceeding 90 min increase risk of metabolic syndrome, while naps of approximately $30 \mathrm{~min}$ may protect against it. Different categorization of siesta length complicates comparison between studies.

\subsection{Interpretation of Findings Related to Metabolic Syndrome Components}

\subsubsection{Obesity}

We found that average daily siesta of more than 30 min duration was positively associated with obesity (aOR 1.15, 95\% CI 1.01-1.32). Several cross-sectional studies have similarly associated longer siesta with obesity [42,44-46], however one Chinese crosssectional study into on a related outcome associated a $0.1-1 \mathrm{hr}$ nap habit with reduced risk 
of being overweight as determined by BMI $\geq 25 \mathrm{~kg} / \mathrm{m}^{2}$ [47] and a previous prospective study from our own SUN cohort found that daily siesta of $30 \mathrm{~min}$ was associated with decreased risk of obesity (HR 0.67; 95\% CI 0.46-0.96) [35]. This apparent difference between two studies from the same cohort stems from the different methods of measuring obesity (the previous study using BMI rather than waist circumference); different sampled populations (the previous study excluded only participants with obesity at baseline, whereas we excluded participants with any metabolic syndrome criteria); and different categorization of siesta (the prior study had separate groups for siesta equal to $30 \mathrm{~min}$ and siesta greater than $30 \mathrm{~min}$, but in our study these two categories were combined).

\subsubsection{Triglycerides}

We found that daily siesta averaging more than 30 min duration increased the risk of high triglycerides (aOR 1.33, 95\% CI 1.00-1.76). Positive associations between longer and more frequent siesta and high triglycerides have been previously described in crosssectional studies $[41,42,48]$.

\subsubsection{Remaining Metabolic Syndrome Criteria}

We did not find any relationship between siesta length and blood pressure or siesta length and elevated blood glucose, despite previous studies demonstrating positive associations between longer siesta and type 2 diabetes mellitus [49,50] and between siesta over $30 \mathrm{~min}$ and hypertension [51]. In our study, point estimates for the relationship between siesta over $30 \mathrm{~min}$ and these outcomes were positive, but the $95 \%$ confidence intervals crossed the value for null effect and the $p$ value was high. Similarly, our data for LDH cholesterol did not demonstrate any significant relationship.

\subsection{Limitations}

Our findings are limited by the complexity of defining a variable to analyze siesta exposure. We defined our exposure variable as the average daily siesta duration across a week, however in doing so we blurred the possibly pertinent distinction between duration of a single siesta and frequency of siesta practice across the week. In sensitivity analysis we created alternate variables that focused on frequency of siesta length, thereby preserving the distinction between these two characteristics of exposure. These sensitivity analyses confirmed our main finding that daily siesta of greater than 30 min increases risk of metabolic syndrome. Furthermore, it supported a suggestion that siesta of less than or equal to $30 \mathrm{~min}$ duration seems to confer some protection against metabolic syndrome, while siesta of over $30 \mathrm{~min}$ does not.

Our categorization of siesta was also limited by our inability to guarantee stable siesta habits over time. Baseline assessment of siesta occurred at the mean age of 35, Furthermore, the chances that an individual would be able to maintain a consistent siesta habit over time is increased in the Spanish context because the siesta is a socially integrated practice. Nonetheless, changing employment, changing seniority within the same employment (especially in the health care setting), and changing stages of life are likely to affect a person's ability to practice consistent siesta, and the resultant categorisation error could strongly influence our results. The effect of this error would most likely would push our results toward the null hypothesis, however it could also introduce a new variable that we have not accounted for. In practice, our age stratified analysis found that, compared to No Siesta, Long Siesta significantly increased risk of metabolic syndrome for participants aged $<50$ at baseline, those whose siesta habit would be most likely to be changeable.

Another potential limitation of our study is our reliance on self-reported data. However, the data relating to siesta has been previously validated using prospective records and was found to have an acceptable intraclass correlation coefficient [35]. In addition, selfreported measurements of metabolic syndrome components and diagnosis of metabolic syndrome have been validated in this cohort, yielding sensitivity of $66 \%$ and specificity of $98 \%$ for diagnosis of metabolic syndrome and good validity for research with positive 
and negative predicative values of over $90 \%$ [38,52]. In any case, the error potentially introduced by self-reporting would be expected to be non-differential as the bias introduced would tend toward the null hypothesis. As such, it should not undermine our positive findings.

Most importantly, we were restricted in our ability to analyze different lengths of siesta less than $30 \mathrm{~min}$ as our data collection questionnaire did not provide sufficient detail to separate different lengths of siesta under $30 \mathrm{~min}$.

\subsection{Strengths}

The strengths of the present study include its dynamic participation, prospective design, long follow-up period, and high retention rate. We were also able to adjust for many relevant covariables, including those related to night-time sleep duration and quality-which other studies have been unable to adjust for, as well as important aspects of diet and lifestyle, and relevant other health conditions. Further, our cohort is drawn from a highly educated sub-section of the Spanish population, which may further help us to minimize confounding related to socio-economic differences. Our ability to minimize the effect of confounders improves the generalizability of our results so that we may cautiously apply them to other Mediterranean adults free from metabolic syndrome components.

\subsection{Biological Explanation}

It has often been suggested that siesta is associated with cardiovascular mortality due to ongoing harm exerted by the rise in blood pressure and the cardiometabolic changes that occur upon waking $[12,14,16]$. This theory suggests that taking siesta increases the number of times per day that one wakes up from sleep, and thereby increases related cardiovascular risk [53].

Yet this theory does not explain the relationships we observed. We did not find any significant association between siesta and elevated blood pressure, and we were not studying the outcome of cardiovascular mortality. Perhaps this often-cited theory may be most relevant in people who already have hypertension or cardiovascular disease at the time of exposure to siesta, and for this reason did not apply to our sample which was free from such diseases at baseline exposure.

It is our opinion that a large part of the biological explanation for the observed association between siesta and metabolic syndrome will be found in the study of circadian rhythm [54-56]. Circadian rhythmicity strongly affects sleep timing and quality as well as energy intake, energy expenditure, and physiological responses to food. Circadian disruption has been found to impair glucose tolerance, reduce energy expenditure, and increase appetite and energy intake [55-58]. Circadian disruption-in the form of social jetlag, shift work, and exposure to light at night—has also been associated with metabolic syndrome, weight gain, and cardiovascular mortality [55,56,58,59]. We propose that siesta may disrupt circadian rhythmicity either through daytime exposure to darkness [55] or if its duration exceeds the duration of the dip in cortisol that is believed to occur physiologically in the early afternoon.

\subsection{Conclusions}

Media coverage often reports the benefits of siesta in improving cognition, alertness, mood, and productivity. But the public is less likely to be aware of studies linking siesta with cardiovascular risk and obesity. As greater numbers of people work from home, partial or unbalanced representations of the impacts of siesta could encourage more people to take siesta, under the impression it may benefit their health.

As such, it is crucial to share evidence that long siesta can increase the risk of obesity and cardiovascular disease, even in healthy individuals. The public would benefit from advice that siesta should be taken occasionally and limited to less than $30 \mathrm{~min}$. They should also be made aware of other ways to boost afternoon alertness and cognition, such as exercise or brisk walking, and health professionals should emphasize the benefits of getting 
enough sleep at night. For those experiencing sleep disorders, methods other than siesta should be recommended to minimize negative impacts of sleep deficit.

However, given that advice to boost productivity often recommends short naps of 10-20 min, it seems possible that cognitive benefits and cardiovascular concerns could be balanced. More research needs to be done to identify what duration of siesta could reduce cardiac risk factors while benefiting cognitive function.

Supplementary Materials: The following are available online at https:/ /www.mdpi.com/article/ 10.3390/nu13114182/s1, Table S1: Sensitivity Analyses.

Author Contributions: A.K.G.: formal analysis, methodology, project administration, software, validation, visualization, writing original draft. C.S.-O.: validation, review and editing. M.B.-R.: data curation, investigation, methodology, resources, review and editing. S.N.K.: review and editing. R.S.: conceptualization, review and editing. M.Á.M.-G.: data curation, funding acquisition, investigation, methodology, resources. A.F.-M.: conceptualization, formal analysis, methodology, project administration, software, supervision, validation, visualization, review and editing. All authors have read and agreed to the published version of the manuscript.

Funding: MAMG was supported by and Advanced Research Grant of the European Research Council (Agreement 340918). The SUN Project has received funding from the Spanish GovernmentInstituto de Salud Carlos III, and the European Regional Development Fund (FEDER) (RD 06/0045, CIBER-OBN, Grants PI13/00615, PI10/02658, PI10/02293, PI13/00615, PI14/01668, PI14/01798, PI14/01764, PI17/01795, PI20/00564 and G03/140), the Navarra Regional Government (27/2011, $45 / 2011,122 / 2014)$, and the University of Navarra. The funders had no role in study design, data collection and analysis, decision to publish, or preparation of the manuscript.

Institutional Review Board Statement: The study was conducted according to the guidelines of the Declaration of Helsinki, and approved by the Institutional Review Board of the University of Navarra (2001_30).

Informed Consent Statement: Submission of a completed baseline questionnaire is interpreted as evidence of free and informed consent.

Data Availability Statement: Available upon request to Department of Preventive Medicine and Public Health, School of Medicine, University of Navarra, Pamplona, Spain.

Acknowledgments: We thank the collaboration of other members of the SUN Group: Alonso A, Álvarez-Álvarez I, Balaguer A, Barbagallo M, Barrientos I, Barrio-López MT, Basterra-Gortari FJ, Battezzati A, Bazal P, Benito S, Bertoli S, Bes-Rastrollo M, Beulen Y, Beunza JJ, Buil-Cosiales P, Canales M, Carlos S, Carmona L, Cervantes S, Cristobo C, de Irala J, de la Fuente-Arrillaga C, de la O V, de la Rosa PA, Delgado-Rodríguez M, Díaz-Gutiérrez J, Díez Espino J, Domínguez L, Donat-Vargas C, Donazar M, Eguaras S, Fresán U, Galbete C, García-Arellano A, García López M, Gardeazábal I, Gea A, Gutiérrez Bedmar M, Gomes-Domingos AL, Gómez-Donoso C, Gómez-Gracia E, Goñi E, Goñi L, Guillén F, Henríquez P, Hernández-Hernández A, Hershey MS, Hidalgo-Santamaría M, Hu E, Leone A, Llorca J, López del Burgo C, Marí A, Marques I, Martí A, Martín Calvo N, Martín-Moreno JM, Martínez JA, Martínez-González MA, Martínez-Lapiscina EH, Mendonça R, Menéndez C, Molendijk M, Murphy K, Muñoz M, Núñez-Córdoba JM, Pajares R, Papadaki A, Parletta N, Pérez de Ciriza P, Pérez-Cornago A, Pérez de Rojas J, Pimenta AM, Pons J, Ramallal R, Razquin C, Rico-Campà A, Romanos A, Ruano C, Ruiz-Estigarribia L, Ruiz Zambrana A, Salgado E, San Julián B, Sánchez D, Sánchez-Bayona R, Sánchez-Tainta A, Santiago S, Sayón-Orea C, Schlatter J, Serrano-Martinez M, Toledo E, Toledo J, Tortosa A, Valencia F, Vázquez Z, Zarnowiecki D, Zazpe I. All of them contributed to the building of this cohort and validation of the questionnaires used in this study.

Conflicts of Interest: The authors declare that there is no conflict of interest.

\section{References}

1. Leng, Y.; Wainwright, N.W.J.; Cappuccio, F.P.; Surtees, P.G.; Hayat, S.; Luben, R.; Brayne, C.; Khaw, K.-T. Daytime Napping and the Risk of All-Cause and Cause-Specific Mortality: A 13-Year Follow-up of a British Population. Am. J. Epidemiol. 2014, 179, 1115-1124. [CrossRef] [PubMed]

2. Hublin, C.; Lehtovirta, M.; Partinen, M.; Koskenvuo, M.; Kaprio, J. Napping and the risk of type 2 diabetes: A population-based prospective study. Sleep Med. 2016, 17, 144-148. [CrossRef] 
3. Van der Pal, K.C.; Koopman, A.D.M.; Lakerveld, J.; van der Heijden, A.A.; Elders, P.J.; Beulens, J.W.; Rutters, F. The association between multiple sleep-related characteristics and the metabolic syndrome in the general population: The New Hoorn study. Sleep Med. 2018, 52, 51-57. [CrossRef] [PubMed]

4. Häusler, N.; Haba-Rubio, J.; Heinzer, R.; Marques-Vidal, P. Association of napping with incident cardiovascular events in a prospective cohort study. Heart 2019, 105, 1793-1798. [CrossRef] [PubMed]

5. Langer Research Associates. Sleep in America ${ }^{\circledR}$ Poll 2019: Sleep Health and Scheduling; National Sleep Foundation: Arlington, VA, USA, 2019.

6. Devine, J.K.; Wolf, J.M. Integrating nap and night-time sleep into sleep patterns reveals differential links to health-relevant outcomes. J. Sleep Res. 2016, 25, 225-233. [CrossRef]

7. Ficca, G.; Axelsson, J.; Mollicone, D.J.; Muto, V.; Vitiello, M.V. Naps, cognition and performance. Sleep Med. Rev. 2010, 14, 249-258. [CrossRef] [PubMed]

8. Hayashi, M.; Motoyoshi, N.; Hori, T. Recuperative Power of a Short Daytime Nap With or Without Stage 2 Sleep. Sleep 2005, 28, 829-836.

9. Watling, C.N.; Smith, S.S.; Horswill, M.S. Stop and revive? The effectiveness of nap and active rest breaks for reducing driver sleepiness: Nap and active rest breaks. Psychophysiol 2014, 51, 1131-1138. [CrossRef] [PubMed]

10. Philip, P.; Taillard, J.; Moore, N.; Delord, S.; Valtat, C.; Sagaspe, P.; Bioulac, B. The Effects of Coffee and Napping on Nighttime Highway Driving: A Randomized Trial. Ann. Intern. Med. 2006, 144, 785. [CrossRef]

11. Trichopoulos, D.; Tzonou, A.; Christopoulos, C.; Havatzoglou, S.; Trichopoulou, A. Does a Siesta Protect From Coronary Artery Disease? Lancet 1987, 330, 269-270. [CrossRef]

12. Tanabe, N.; Iso, H.; Seki, N.; Suzuki, H.; Yatsuya, H.; Toyoshima, H.; Tamakoshi, A.; JACC Study Group. Daytime napping and mortality, with a special reference to cardiovascular disease: The JACC study. Int. J. Epidemiol. 2010, 39, 233-243. [CrossRef] [PubMed]

13. Campos, H.; Siles, X. Siesta and the risk of coronary heart disease: Results from a population-based, case-control study in Costa Rica. Int. J. Epidemiol. 2000, 29, 429-437. [CrossRef] [PubMed]

14. Stang, A.; Dragano, N.; Moebus, S.; Möhlenkamp, S.; Schmermund, A.; Kälsch, H.; Erbel, R.; Jöckel, K.-H.; Heinz Nixdorf Recall Investigative Group. Midday Naps and the Risk of Coronary Artery Disease: Results of the Heinz Nixdorf Recall Study. Sleep 2012, 35, 1705-1712. [CrossRef] [PubMed]

15. Yan, B.; Li, J.; Li, R.; Gao, Y.; Zhang, J.; Wang, G. Association of daytime napping with incident cardiovascular disease in a community-based population. Sleep Med. 2019, 57, 128-134. [CrossRef]

16. Bursztyn, M.; Ginsberg, G.; Hammerman-Rozenberg, R.; Stessman, J. The Siesta in the Elderly: Risk Factor for Mortality? Arch. Intern. Med. 1999, 159, 1582. [CrossRef] [PubMed]

17. Bursztyn, M.; Ginsberg, G.; Stessman, J. The Siesta and Mortality in the Elderly: Effect of Rest Without Sleep and Daytime Sleep Duration. Sleep 2002, 25, 187-191. [CrossRef]

18. Burazeri, G.; Gofin, J.; Kark, J.D. Siesta and Mortality in a Mediterranean Population: A Community Study in Jerusalem. Sleep 2003, 26, 578-584. [CrossRef]

19. Bursztyn, M.; Stessman, J. The Siesta and Mortality: Twelve Years of Prospective Observations in 70-Year-Olds. Sleep 2005, 28, 345-347. [PubMed]

20. Stone, K.L.; Ewing, S.K.; Ancoli-Israel, S.; Ensrud, K.E.; Redline, S.; Bauer, D.C.; Cauley, J.A.; Hillier, T.A.; Cummings, S.R. Self-Reported Sleep and Nap Habits and Risk of Mortality in a Large Cohort of Older Women: Sleep predicts mortality in older women. J. Am. Geriatr. Soc. 2009, 57, 604-611. [CrossRef]

21. Liu, X.; Zhang, Q.; Shang, X. Meta-Analysis of Self-Reported Daytime Napping and Risk of Cardiovascular or All-Cause Mortality. Med. Sci. Monit. 2015, 21, 1269-1275. [PubMed]

22. Zhong, G.; Wang, Y.; Tao, T.; Ying, J.; Zhao, Y. Daytime napping and mortality from all causes, cardiovascular disease, and cancer: A meta-analysis of prospective cohort studies. Sleep Med. 2015, 16, 811-819. [CrossRef] [PubMed]

23. Mottillo, S.; Filion, K.B.; Genest, J.; Joseph, L.; Pilote, L.; Poirier, P.; Rinfret, S.; Schiffrin, E.L.; Eisenberg, M.J. The Metabolic Syndrome and Cardiovascular Risk. J. Am. Coll. Cardiol. 2010, 56, 1113-1132. [CrossRef] [PubMed]

24. Ford, E.S. Risks for All-Cause Mortality, Cardiovascular Disease, and Diabetes Associated With the Metabolic Syndrome: A summary of the evidence. Diabetes Care 2005, 28, 1769-1778. [CrossRef]

25. Alberti, K.G.M.M.; Eckel, R.H.; Grundy, S.M.; Zimmet, P.Z.; Cleeman, J.I.; Donato, K.A.; Fruchart, J.-C.; James, W.P.T.; Loria, C.M.; Smith, S.C. Harmonizing the Metabolic Syndrome: A Joint Interim Statement of the International Diabetes Federation Task Force on Epidemiology and Prevention; National Heart, Lung, and Blood Institute; American Heart Association; World Heart Federation; International Atherosclerosis Society; and International Association for the Study of Obesity. Circulation 2009, 120, 1640-1645. [PubMed]

26. Sattar, N.; McConnachie, A.; Shaper, A.G.; Blauw, G.J.; Buckley, B.M.; de Craen, A.J.; Ford, I.; Forouhi, N.G.; Freeman, D.J.; Jukema, J.W.; et al. Can metabolic syndrome usefully predict cardiovascular disease and diabetes? Outcome data from two prospective studies. Lancet 2008, 371, 1927-1935. [CrossRef]

27. Esposito, K.; Chiodini, P.; Colao, A.; Lenzi, A.; Giugliano, D. Metabolic Syndrome and Risk of Cancer: A systematic review and meta-analysis. Diabetes Care 2012, 35, 2402-2411. [CrossRef] [PubMed] 
28. Esposito, K.; Chiodini, P.; Capuano, A.; Bellastella, G.; Maiorino, M.I.; Rafaniello, C.; Panagiotakos, D.B.; Giugliano, D. Colorectal cancer association with metabolic syndrome and its components: A systematic review with meta-analysis. Endocrine 2013, 44, 634-647. [CrossRef] [PubMed]

29. Elsamna, S.; Elkattawy, O.; Merchant, A.M. Association of metabolic syndrome with morbidity and mortality in emergency general surgery. Am. J. Surg. 2020, 220, 448-453. [CrossRef] [PubMed]

30. Lak, K.L.; Helm, M.C.; Kindel, T.L.; Gould, J.C. Metabolic Syndrome Is a Significant Predictor of Postoperative Morbidity and Mortality Following Bariatric Surgery. J. Gastrointest. Surg. 2019, 23, 739-744. [CrossRef] [PubMed]

31. Pal, K.; Mukadam, N.; Petersen, I.; Cooper, C. Mild cognitive impairment and progression to dementia in people with diabetes, prediabetes and metabolic syndrome: A systematic review and meta-analysis. Soc. Psychiatry Psychiatr. Epidemiol. 2018, 53, 1149-1160. [CrossRef] [PubMed]

32. Yaffe, K.; Kanaya, A.; Lindquist, K.; Simonsick, E.M.; Harris, T.; Shorr, R.I.; Tylavsky, F.A.; Newman, A.B. The Metabolic Syndrome, Inflammation, and Risk of Cognitive Decline. JAMA 2004, 292, 2237-2242. [CrossRef]

33. Wang, J.; Sarnola, K.; Ruotsalainen, S.; Moilanen, L.; Lepistö, P.; Laakso, M.; Kuusisto, J. The metabolic syndrome predicts incident congestive heart failure: A 20-year follow-up study of elderly finns. Atherosclerosis 2010, 210, 237-242. [CrossRef] [PubMed]

34. Yamada, T.; Shojima, N.; Yamauchi, T.; Kadowaki, T. J-curve relation between daytime nap duration and type 2 diabetes or metabolic syndrome: A dose-response meta-analysis. Sci. Rep. 2016, 6, 38075. [CrossRef] [PubMed]

35. Sayón-Orea, C.; Bes-Rastrollo, M.; Carlos, S.; Beunza, J.J.; Basterra-Gortari, F.J.; Martínez-González, M.A. Association between Sleeping Hours and Siesta and the Risk of Obesity: The SUN Mediterranean Cohort. Obes. Facts 2013, 6, 337-347. [CrossRef] [PubMed]

36. Carlos, S.; De La Fuente-Arrillaga, C.; Bes-Rastrollo, M.; Razquin, C.; Rico-Campà, A.; Martínez-González, M.; Ruiz-Canela, M. Mediterranean Diet and Health Outcomes in the SUN Cohort. Nutrients 2018, 10, 439. [CrossRef]

37. Willett, W. Nutritional Epidemiology, 3rd ed.; Oxford University Press: New York, NY, USA, 2013.

38. Fernández-Montero, A.; Beunza, J.J.; Bes-Rastrollo, M.; Barrio, M.T.; de la Fuente-Arrillaga, C.; Moreno-Galarraga, L.; MartínezGonzález, M.A. Validación de los componentes del síndrome metabólico autodeclarados en un estudio de cohortes. Gac. Sanit. 2011, 25, 303-307. [CrossRef]

39. Trichopoulou, A.; Costacou, T.; Bamia, C.; Trichopoulos, D. Adherence to a Mediterranean Diet and Survival in a Greek Population. N. Engl. J. Med. 2003, 348, 2599-2608. [CrossRef]

40. Consensus Conference Panel; Watson, N.F.; Badr, M.S.; Belenky, G.; Bliwise, D.L.; Buxton, O.M.; Buysse, D.; Dinges, D.F.; Gangwisch, J.; Grandner, M.A.; et al. Recommended Amount of Sleep for a Healthy Adult: A Joint Consensus Statement of the American Academy of Sleep Medicine and Sleep Research Society. J. Clin. Sleep Med. 2015, 11, 591-592. [CrossRef] [PubMed]

41. He, J.; Ouyang, F.; Qiu, D.; Duan, Y.; Luo, D.; Xiao, S. Association of Nap Duration after Lunch with Prevalence of Metabolic Syndrome in a Chinese Government Employee Population. IJERPH 2020, 17, 4268. [CrossRef]

42. Lin, D.; Sun, K.; Li, F.; Qi, Y.; Ren, M.; Huang, C.; Tang, J.; Xue, S.; Li, Y.; Yan, L. Association between habitual daytime napping and metabolic syndrome: A population-based study. Metabolism 2014, 63, 1520-1527. [CrossRef]

43. Yang, L.; Xu, Z.; He, M.; Yang, H.; Li, X.; Min, X.; Zhang, C.; Xu, C.; Angileri, F.; Légaré, S.; et al. Sleep Duration and Midday Napping with 5-Year Incidence and Reversion of Metabolic Syndrome in Middle-Aged and Older Chinese. Sleep 2016, 39, 1911-1918. [CrossRef]

44. Ghazizadeh, H.; Mobarra, N.; Esmaily, H.; Seyedi, S.M.R.; Amiri, A.; Rezaeitalab, F.; Mokhber, N.; Moohebati, M.; Ebrahimi, M.; Tayebi, M.; et al. The association between daily naps and metabolic syndrome: Evidence from a population-based study in the Middle-East. Sleep Health 2020, 6, 684-689. [CrossRef]

45. Loredo, J.S.; Weng, J.; Ramos, A.R.; Sotres-Alvarez, D.; Simonelli, G.; Talavera, G.A.; Patel, S.R. Sleep Patterns and Obesity. Chest 2019, 156, 348-356. [CrossRef]

46. Ramos, A.R.; Weng, J.; Wallace, D.M.; Petrov, M.R.; Wohlgemuth, W.K.; Sotres-Alvarez, D.; Loredo, J.S.; Reid, K.J.; Zee, P.C.; Mossavar-Rahmani, Y.; et al. Sleep Patterns and Hypertension Using Actigraphy in the Hispanic Community Health Study/Study of Latinos. Chest 2018, 153, 87-93. [CrossRef] [PubMed]

47. Chen, M.; Zhang, X.; Liang, Y.; Xue, H.; Gong, Y.; Xiong, J.; He, F.; Yang, Y.; Cheng, G. Associations between nocturnal sleep duration, midday nap duration and body composition among adults in Southwest China. PLoS ONE 2019, 14, e0223665. [CrossRef] [PubMed]

48. Hubert Lam, K.; Jiang, C.Q.; Thomas, G.N.; Arora, T.; Zhang, W.S.; Taheri, S.; Adab, P.; Lam, T.H.; Cheng, K.K. Napping Is Associated with Increased Risk of Type 2 Diabetes: The Guangzhou Biobank Cohort Study. Sleep 2010, 33, 402-407. [CrossRef] [PubMed]

49. Guo, V.Y.; Cao, B.; Wong, C.K.H.; Yu, E.Y.T. The association between daytime napping and risk of diabetes: A systematic review and meta-analysis of observational studies. Sleep Med. 2017, 37, 105-112. [CrossRef]

50. Chen, G.-C.; Liu, M.-M.; Chen, L.-H.; Xu, J.-Y.; Hidayat, K.; Li, F.-R.; Qin, L.-Q. Daytime napping and risk of type 2 diabetes: A meta-analysis of prospective studies. Sleep Breath 2018, 22, 815-824. [CrossRef] [PubMed]

51. Cao, Z.; Shen, L.; Wu, J.; Yang, H.; Fang, W.; Chen, W.; Yuan, J.; Wang, Y.; Liang, Y.; Wu, T. The effects of midday nap duration on the risk of hypertension in a middle-aged and older Chinese population: A preliminary evidence from the Tongji-Dongfeng Cohort Study, China. J. Hypertens 2014, 32, 1993-1998. [CrossRef] [PubMed] 
52. Barrio-Lopez, M.T.; Bes-Rastrollo, M.; Beunza, J.J.; Fernandez-Montero, A.; Garcia-Lopez, M.; Martinez-Gonzalez, M.A. Validation of metabolic syndrome using medical records in the SUN cohort. BMC Public Health 2011, 11, 867. [CrossRef] [PubMed]

53. Crnko, S.; Du Pré, B.C.; Sluijter, J.P.G.; Van Laake, L.W. Circadian rhythms and the molecular clock in cardiovascular biology and disease. Nat. Rev. Cardiol. 2019, 16, 437-447. [CrossRef] [PubMed]

54. Maury, E.; Hong, H.K.; Bass, J. Circadian disruption in the pathogenesis of metabolic syndrome. Diabetes Metab. 2014, 40, 338-346. [CrossRef] [PubMed]

55. Bedrosian, T.A.; Fonken, L.K.; Nelson, R.J. Endocrine Effects of Circadian Disruption. Annu. Rev. Physiol. 2016, 78, 109-131. [CrossRef] [PubMed]

56. Engin, A.B.; Engin, A. (Eds.) Advances in experimental medicine and biology. In Obesity and Lipotoxicity; Springer International Publishing: Cham, Switzerland, 2017; Volume 960, ISBN 978-3-319-48380-1.

57. Reutrakul, S.; Van Cauter, E. Sleep influences on obesity, insulin resistance, and risk of type 2 diabetes. Metabolism 2018, 84, 56-66. [CrossRef]

58. Scheer, F.A.J.L.; Hilton, M.F.; Mantzoros, C.S.; Shea, S.A. Adverse metabolic and cardiovascular consequences of circadian misalignment. Proc. Natl. Acad. Sci. USA 2009, 106, 4453-4458. [CrossRef]

59. West, A.C.; Smith, L.; Ray, D.W.; Loudon, A.S.I.; Brown, T.M.; Bechtold, D.A. Misalignment with the external light environment drives metabolic and cardiac dysfunction. Nat. Commun. 2017, 8, 417. [CrossRef] 